\title{
Assessing Frozen Section Surgical Margin Status in Oral Squamous Cell Carcinoma
}

\author{
Deep R. Viswasini ${ }^{1}$, Kanchi Ravi Don ${ }^{2}$, Herald J. Sherlin³ ${ }^{3}$ Gifrina Jayaraj ${ }^{4}$, Archana Santhanam ${ }^{5}$ \\ 1,2,3,4,5 Department of Oral and Maxillofacial Pathology, Saveetha Dental College and Hospitals, \\ SIMATS, Chennai, Tamilnadu, India.
}

\section{ABSTRACT}

\section{BACKGROUND}

A key technique that is used by the pathologists during intraoperative consultation is frozen section evaluation. It is very important for the surgeons to know if the surgical margin is clear of malignant cells and the status of dysplasia during oncosurgery. There should be concordance between the frozen section margin and paraffin-embedded section. The purpose of the study was to evaluate and validate the accuracy of frozen section surgical margin status in oral squamous cell carcinoma (OSCC) among 2 observers.

\section{METHODS}

A total of 25 histologically diagnosed OSCC cases from April 2018 to April 2019 were included in the study. A total of 122 surgical margin slides (61 frozen sections and paraffin-embedded slides) were retrieved. The interobserver agreement of frozen section margin status with paraffin-embedded was analyzed.

\section{RESULTS}

Interobserver agreement in frozen section margin was $73.80 \%$ with a kappa value of 0.048 (slight) and P-value 0.344. The interobserver agreement for paraffinembedded margin was $93.40 \%$ with a kappa value of 0.572 (moderate) and P-value 0.005 . The concordance between frozen and paraffin section by observer 1 was $85.20 \%$ and by observer 2 was $95.10 \%$.

\section{CONCLUSIONS}

The rate of discordant will get reduced by accurate sampling along with better communication between pathologist and surgeon and at times of uncertainty, a second pathologist's opinion can be considered for re-evaluating the interpretations.

\section{KEY WORDS}

Frozen Section Margin Status, Interobserver, Paraffin Embedded Margin Status, OSCC.
Corresponding Author: Dr. Deep R. Viswasini, III MDS, Post Graduate Student Department of Oral and Maxillofacial Pathology, Saveetha Dental College and Hospitals, SIMATS, Chennai, Tamilnadu, India. E-mail: deepadentalv1994@gmail.com

DOI: $10.14260 / \mathrm{jemds} / 2021 / 735$

How to Cite This Article:

Viswasini DR, Don KR, Sherlin HJ, et al. Assessing frozen section surgical margin status in oral squamous cell carcinoma. J Evolution Med Dent Sci 2021;10(42):36233627, DOI: 10.14260/jemds/2021/735

Submission 22-09-2020,

Peer Review 01-10-2021,

Acceptance 07-10-2021,

Published 18-10-2021.

Copyright (c) 2021 Deep R. Viswasini et al. This is an open access article distributed under Creative Commons Attribution License [Attribution 4.0 International (CC BY 4.0)] 


\section{BACKGROUND}

Oral cancer is one of the major public health problems accounting for $30 \%$ in India, the sixth most common malignancy worldwide and it ranks among the top three types of cancer in the country.1-2 Oral habits like betel quid chewing, smoking, alcohol consumption, genetic mutations are the main etiologies for oral cancer. The three major therapeutic strategies for oral squamous cell carcinoma are surgery, irradiation and chemotherapy. Surgery is the first choice of treatment for oral cancer even though various anticancer agents including molecular target drugs are available. $^{3}$ The main purpose of surgery is to remove the tumour with oncologically safe surgical margins.

In case of intraoperative diagnosis of newly discovered lesions as well as diagnosis of confirmation diagnosis in the previously biopsied pathological process and to establish the extent of the disease, frozen section evaluation is considered to be the standard procedure which has shown sufficient accuracy. When the patient is on the operating table, a crucial role is being played by the intraoperative frozen section in the surgical management by providing important pathological information of the patient. 4 This technique decreases the need for reoperation by evaluating the surgical margin, checking the tumour clearance and guiding the surgeon in making an immediate decision on the extent and adequacy of the surgical procedure. 5 The use of frozen section evaluation in ensuring negative margins for resection of head and neck squamous cell carcinomas has been published as detailed protocols. ${ }^{6}$ At the time of frozen section, apart from surgical margins, the surgeon also has the opportunity to know the precise $\mathrm{T}$ size and the tumour thickness as predictors of the occult lymph node metastases ${ }^{7}$ and also allows the surgeons to make a critical decision of neck dissection whenever in dilemma. Frozen section concordance rates with permanent diagnosis average is approximately $98 \% .{ }^{8}$ The accuracy of the frozen section and paraffin-embedded section is said to be $96.7 \% .{ }^{9}$ The concordance rate varies by site, with that of the ovary being approximately $93 \%{ }^{10-11}$ and lower at other sites such as the skin. ${ }^{12}$ Less data is available for the head and neck area. Epithelial dysplasia is characterized by atypical microscopic changes in the epithelium that can include but are not limited to prominent nucleoli, hyperchromatic nuclei, nuclear pleomorphism, altered nuclear/cytoplasmic ratios, increased atypical mitotic activity, increased individual cell characterization, basal cell hyperplasia, and basal layer budding. Epithelial dysplasia is graded as mild, moderate, severe dysplasia and carcinoma in situ. Distinctions between the grades are made based on histological evaluation. Knowledge of the degree of dysplasia assists with decision making and helps to predict whether the lesion will progress to cancer or will resolve on its own after removal of the source of the irritant. The fact that the diagnostic grading of epithelial dysplasia has never attained unanimity amongst pathologists is a worrisome picture. The considerable variations in grading epithelial dysplasia might be due to the lack of objectivity in the evaluation of established criteria, the arbitrary division of the grading, lack of calibration of criteria and grading, and lack of sufficient knowledge of which criteria are important for the prediction of malignant potential. There are hardly any studies analysing the interobserver agreement in frozen sections.

So the intention of the study was to determine the interobserver agreement in frozen section margin status and compare it with the interobserver agreement in paraffinembedded section margin status. Also to assess and compare the concordance of frozen section margin status with corresponding paraffin-embedded section margin status.

\section{METHODS}

We retrospectively reviewed the frozen section cases performed in Oral and Maxillofacial Pathology Laboratory, Saveetha Dental College and Hospital from April 2018 to April 2019. Approval was taken from the Institutional Review board. A total of 25 histologically diagnosed OSCC cases were included in the study where 11 cases were OSCC of tongue, 5 buccal mucosa, 5 gingivobuccal sulcus, 2 maxilla and 2 retromolar trigones. The sample size was calculated based on the previous reference ${ }^{8}$ with the power of study set as $80 \%$. Surgical margins with intact epithelium were included in the study and the core of the lesion was excluded in the study. A total of 122 surgical margin slides (61 frozen section slides and 61 paraffin-embedded slides) were retrieved. These slides were cross-checked from confirmation.

Patient files in the Pathology department provided data regarding the frozen section case. Frozen section surgical margins and the corresponding paraffin-embedded surgical margins were observed by two oral pathologists for the margin status. Blinding was done to avoid bias.

The interobserver agreements in frozen section margin status, and paraffin-embedded section margin status, concordance of frozen section margin status with paraffinembedded section margin status were observed and tabulated and statistically analysed. Clearance status and the grading of dysplasia were done by the 2 observers for both frozen section surgical margin slides and paraffin-embedded surgical margin slides. Clearance status was graded as (absence of malignant epithelial cells) clearance adequate and (presence of malignant epithelial cells) clearance inadequate. Dysplasia grading was done based on WHO 2017 classification as mild dysplasia, moderate dysplasia and severe dysplasia.13-26 Clearance status and grading of dysplasia were tabulated and analysed.

\section{Statistical Analysis}

The test results were categorized into concordant and discordant groups. IBM. SPSS statistics software 23.0 version was used to analyse the collected data and interobserver agreement was assessed using Kappa statistics (Cohen's kappa). The P-value $<0.05$ was considered statistically significant.

\section{RESULTS}

In this study, 61 surgical section slides from both frozen sections and paraffin-embedded sections were analysed. Interobserver agreement in frozen section surgical margin 
was $73.80 \%$ with a kappa value of 0.048 (slight) and a Pvalue of 0.344 . The interobserver agreement for paraffinembedded surgical margin was $93.40 \%$ with a kappa value of 0.572 (moderate) and a P-value of 0.005 (Table 1). The concordance between frozen and paraffin sections by observer 1 was $85.20 \%$ and $95.10 \%$ by observer 2 (Table 2).

\begin{tabular}{|cccc|}
\hline & $\begin{array}{c}\text { Number of } \\
\text { Slides (N) }\end{array}$ & $\begin{array}{c}\text { Agreement } \\
\text { Percentage } \\
(\%)\end{array}$ & $\begin{array}{c}\text { Disagreement } \\
\text { Percentage } \\
(\%)\end{array}$ \\
$\begin{array}{c}\text { Frozen section surgical } \\
\text { margin status }\end{array}$ & 61 & $74 \%$ & $26 \%$ \\
$\begin{array}{c}\text { Paraffin embedded surgical } \\
\text { margin status }\end{array}$ & 61 & $93 \%$ & $7 \%$ \\
\hline $\begin{array}{c}\text { Table 1. Table Depicting the Interobserver Agreement on Frozen } \\
\text { Section Surgical Margin and Paraffin-Embedded Surgical Margin }\end{array}$ \\
\hline
\end{tabular}

\begin{tabular}{|cccc|}
\hline & $\begin{array}{c}\text { Number } \\
\text { of } \\
\text { Slides }\end{array}$ & $\begin{array}{c}\text { Concordance } \\
\text { Percentage } \\
\text { (\%) }\end{array}$ & $\begin{array}{c}\text { Discrepancy } \\
\text { Percentage } \\
(\%)\end{array}$ \\
$\begin{array}{c}\text { Frozen section surgical margin } \\
\text { and paraffin-embedded section } \\
\text { margin status by observer 1. }\end{array}$ & 61 & $85 \%$ & $15 \%$ \\
$\begin{array}{c}\text { Frozen section surgical margin } \\
\text { and paraffin-embedded section } \\
\text { margin status by observer 2. }\end{array}$ & 61 & $95 \%$ & $5 \%$ \\
\hline $\begin{array}{c}\text { Table 2. Table Depicting the Concordance of Frozen Section Surgical } \\
\text { Margin and Paraffin-Embedded Surgical Margin by Observer 1 and } \\
\text { Observer 2. }\end{array}$ \\
\hline
\end{tabular}

\section{DISCUSSION}

The surgeon's confidence in frozen section results relies mainly on the diagnostic accuracy of the procedure. ${ }^{14}$ Frozen section diagnosis is the intraoperative method which is usually compared to permanent hematoxylin and eosin stained section diagnosis to evaluate the diagnostic accuracy. Evaluating discrepancies, identifying deficiencies and resolving the underlying problems can improve the accuracy of the frozen section. ${ }^{3}$ Reasons for diagnostic discrepancies generally fall into one of the following categories: technical problems, sampling errors or interpretation errors. ${ }^{15}$

The main errors in diagnosis are often in recognition of certain types of lesions, inadequate sampling, technical problems or the lack of communication between the surgeon and the pathologist.16,17 Several comparative studies regarding frozen and paraffin sections have been performed to detect the frozen sections in the diagnosis of prostate carcinoma, breast cancer, lung cancer, skin cancer and tumours of the colon, gallbladder, kidney, head and neck. ${ }^{18}$

Various studies on the interobserver accuracy of the grades on dysplasia are Abbey et al. interobserver accuracyslight $(\mathrm{K}=0.17)$, Brothwell $\mathrm{DJ}$ et al. - fair agreement $(\mathrm{K}=$ 0.37), Kujan $O$ et al. - slight to mild agreement ( $\mathrm{K}=0.06$ to 0.43), Karabulut et al. - $49 \%-69 \%$ agreement- $\mathrm{K}=0.27$ to 0.45 (fair agreement). ${ }^{19-22}$ But all of these studies were done for paraffin embedding histopathological slides, not on frozen section slides. That's why our study aims to determine interobserver accuracy of the grades on dysplasia in frozen section slides. It was observed that the discrepancy between the observer was due to basilar hyperplasia, hyperchromatic nucleus, increased nuclear-cytoplasmic ratio and overlapping of basal cells (sectioning errors). Because of the overlapping of basal cells some sections were graded as mild dysplasia by observer 1 , while clear with no dysplasia by observer 2 (indicative of interobserver disagreement) (figure 1).

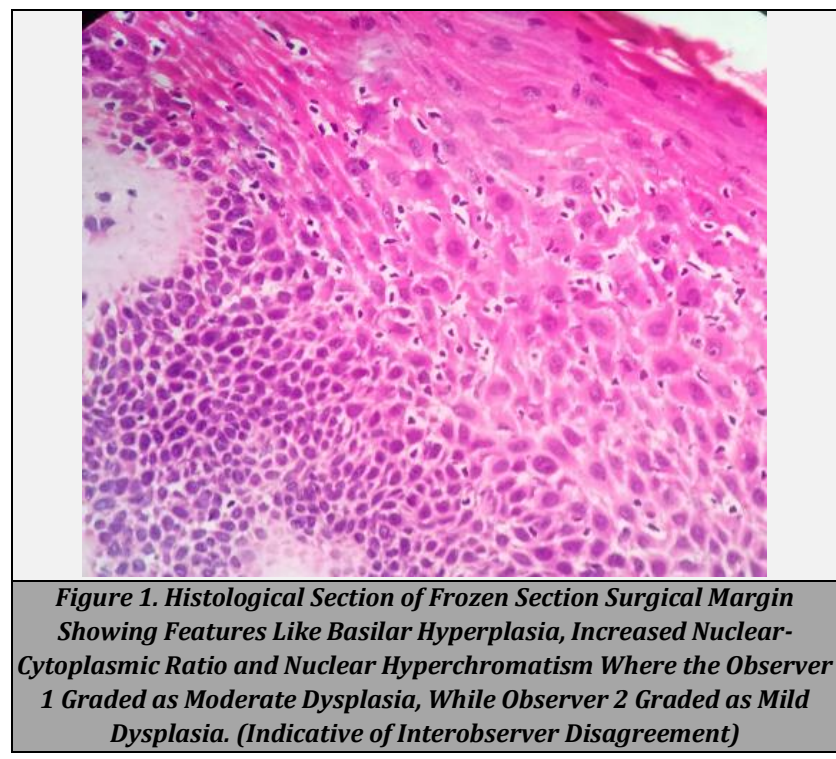

Black et al. reported the frozen section from the pathologist point of view where he stated inaccuracy in the evaluation of the margins. Pathologists require cooperation with surgeons as some resected specimens are not being anatomically oriented and labelled. ${ }^{23}$ There are studies stating that the frozen section is inaccurate for routine investigation of the margins for resected oral cancers other than tongue cancer, as the anatomical structure is complicated and anatomical limits that surgical access to the tumour site is generally poor. ${ }^{24}$
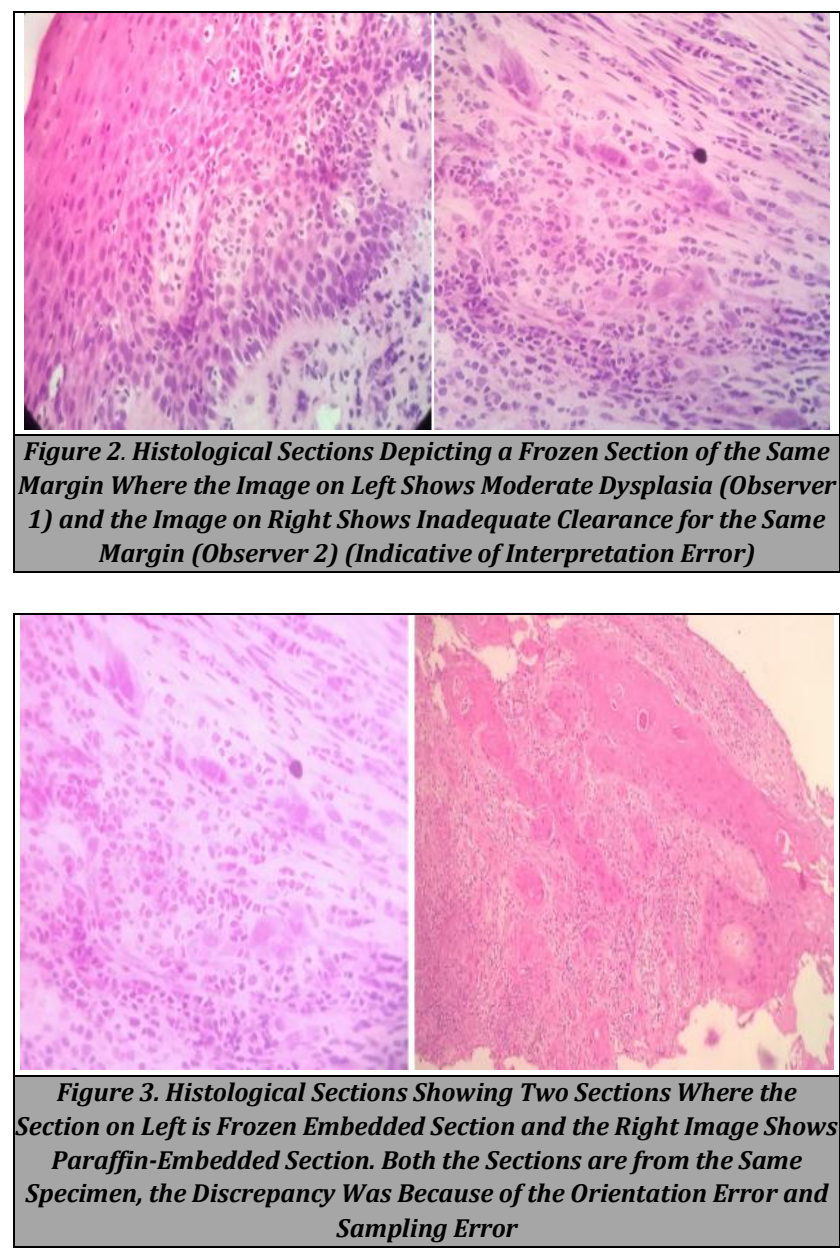
The concordance of frozen section margin status and paraffin-embedded section margin status done by Hatami et al. was $97 \%$ but it was observed to be $85.20 \%$ by one observer and $95.10 \%$ by the other observer. The discrepancy was noted due to sampling error (insufficient sampling, deeper levels in permanent sections) (figure 3) and interpretation error (figure 2). In few concordance studies of the frozen section/permanent section diagnosis, interpretive issues have been reported as the major cause for discrepancies. Insufficient experience is a potential cause of interpretive error in interpreting frozen sections.

The discrepancies in the accuracy of frozen section surgical margin and paraffin section surgical margin could be minimised by inking the margins before fixation, Gandour Edwards et al. (several levels at least 3 of frozen section) and proper discussion with the experienced pathologist. ${ }^{25}$ In the interpretation of frozen sections, experience plays a major role which helps in lowering the deferred and error rate when specimens are interpreted by more experienced pathologists. Evaluation of the specimens by two observers or even three, when there is uncertainty, reduces the rate of error. ${ }^{11}$

Identification of genetic and epigenetic changes that could predict the malignant potential of dysplastic lesions. A better understanding and knowledge of the carcinogenesis process would develop newer strategies to identify gross genomic aberrations on a routine basis. Improved studies on chromosomal, genomic and molecular alterations in the potentially malignant lesions would shift the balance from relying on mere morphological alterations for diagnosis to more authentic and predictive factors that bring about these alterations. ${ }^{26,27}$ Establishing a universal image database for each histological criteria would reduce the shadow of subjectivity in grading, though it may not be completely eliminated.

\section{CONCLUSIONS}

The present study shows that the frozen section is an accurate and reliable method. Accurate, adequate sampling along with better communication between pathologists and surgeons aid to reduce the rate of discordancy. Re-evaluation of the interpretations by a second pathologist when there is uncertainty helps reduce both discordants.

\section{Limitations}

The limitation of the present study is its smaller sample size. Also in the present study, the margin status consisted of only mild dysplasia cases. There were no moderate and severe dysplastic margins noted in the selected cases. So a larger sample size with the inclusion of severe dysplastic margins would give a better rate of concordancy.

Data sharing statement provided by the authors is available with the full text of this article at jemds.com.

Financial or other competing interests: None.

Disclosure forms provided by the authors are available with the full text of this article at jemds.com.

\section{REFERENCES}

[1] Williams HK. Molecular pathogenesis of oral squamous carcinoma. Mol Pathol 2000;53(4):165-72.

[2] Sankaranarayanan R, Ramadas K, Thomas G, et al. Effect of screening on oral cancer mortality in Kerala, India: a cluster-randomised controlled trial. Lancet 2005;365(9475)1927-33.

[3] Yanamoto S, Yamada S, Takahashi $H$, et al. Clinicopathological risk factors for local recurrence in oral squamous cell carcinoma. Int J Oral Maxillofac Surg 2012;41(10):1195-200.

[4] Mahe E, Ara S, Bishara M, et al. Intraoperative pathology consultation: error, cause and impact. Can J Surg 2013;56(3):E13-8.

[5] Arai T. Do we need special viewpoints for intraoperative frozen section diagnosis? Virchows Arch 2020;477(5):761-2.

[6] Williams MD. Determining adequate margins in head and neck cancers: practice and continued challenges. Curr Oncol Rep 2016;18(9):54.

[7] Huang SH, Hwang D, Lockwood G, et al. Predictive value of tumor thickness for cervical lymph-node involvement in squamous cell carcinoma of the oral cavity. Cancer 2009;115(7):1489-97.

[8] Hatami H, Mohsenifar Z, Alavi SN. The diagnostic accuracy of frozen section compared to permanent section: a single center study in Iran. Iran J Pathol 2015;10(4):295-9.

[9] Geramizadeh B, Larijani T, Owji SM, et al. Accuracy of intra-operative frozen section consultation in south of Iran during four years. Indian J Pathol Microbiol 2010;53(3):414-7.

[10] Abudukadeer A, Azam S, Mutailipu A, et al. Knowledge and attitude of Uyghur women in Xinjiang province of China related to the prevention and early detection of cervical cancer. World J Surg Oncol 2015;13:110.

[11] Gorišek B, Stare MR, Krajnc I. Accuracy of intra-operative frozen section analysis of ovarian tumours. J Int Med Res 2009;37(4):1173-8.

[12] Onajin O, Wetter DA, Roenigk RK, et al. Frozen section diagnosis for non-melanoma skin cancers: correlation with permanent section diagnosis. J Cutan Pathol 2015;42(7):459-64.

[13] Jayaraj G, Ramani P, Sherlin HJ, et al. Inter-observer agreement in grading oral epithelial dysplasia - a systematic review. J Oral Maxillofac Surg Med Pathol 2015;27(1):112-6.

[14] Howanitz PJ, Hoffman GG, Zarbo RJ. The accuracy of frozen-section diagnoses in 34 hospitals. Arch Pathol Lab Med 1990;114(4):355-9.

[15] Jaafar H. Intra-operative frozen section consultation: concepts, applications and limitations. Malays J Med Sci 2006;13(1):4-12.

[16] Bone RC. Cancer of the face and mouth pathology and management for surgeons. By Ian A. McGregor and Frances M. McGregor, p. 615. Churchill Livingstone, New York, New York 1986, Head \& Neck Surgery 1987;10(1):68-9.

[17] Don KR, Ramani P, Ramshankar V, et al. Promoter hypermethylation patterns of P16, DAPK and MGMT in 
oral squamous cell carcinoma: a systematic review and meta-analysis. Indian J Dent Res 2014;25(6):797-805.

[18] Prey MU, Vitale T, Martin SA. Guidelines for practical utilization of intraoperative frozen sections. Arch Surg 1989;124(3):331-5.

[19] Abbey LM, Kaugars GE, Gunsolley JC, et al. Intraexaminer and interexaminer reliability in the diagnosis of oral epithelial dysplasia. Oral Surg Oral Med Oral Pathol Oral Radiol Endodontol 1995;80(2):188-91.

[20] Brothwell DJ, Lewis DW, Bradley G, et al. Observer agreement in the grading of oral epithelial dysplasia. Community Dent Oral Epidemiol 2003;31(4):300-5.

[21] Kujan O, Oliver RJ, Khattab A, et al. Evaluation of a new binary system of grading oral epithelial dysplasia for prediction of malignant transformation. Oral Oncol 2006;42(10):987-93.

[22] Karabulut A, Reibel J, Therkildsen MH, et al. Observer variability in the histologic assessment of oral premalignant lesions. J Oral Pathol Med 1995;24(5):198200.
[23] Black C, Marotti J, Zarovnaya E, et al. Critical evaluation of frozen section margins in head and neck cancer resections. Cancer 2006;107(12):2792-800.

[24] Gerber S, Gengler C, Grätz KW, et al. The impact of frozen sections on final surgical margins in squamous cell carcinoma of the oral cavity and lips: a retrospective analysis over an 11 years period. Head Neck Oncol 2011;3:56.

[25] Gandour-Edwards RF, Donald PJ, Lie JT. Clinical utility of intraoperative frozen section diagnosis in head and neck surgery: a quality assurance perspective. Head Neck 1993;15(5):373-6.

[26] Bedre AS, Don KR. Different grading systems of oral squamous cell carcinoma and their relation to lymph node metastasis - a comparative study. International Journal of Current Research 2017;9(5)50458-64.

[27] Nadar S, Don KR. Metastatic tumours to the jaw and oral cavity - a brief review. International Journal of Current Research 2017;9(5):50362-66. 